\title{
VIOLÊNCIA E VULNERABILIDADES: \\ OS JOVENS E AS NOTÍCIAS DE JORNAL ${ }^{1}$ \\ Carolina Salomão Corrêa ${ }^{\star}$
Solange Jobim e Souza
}

\section{Resumo}

No Brasil, do total de homicídios ocorridos no pais, em aproximadamente $56 \%$, as vítimas têm idade entre 15 e 29 anos. A pesquisa partiu da coleta e reunião de noticias de jornais referentes a situações de óbitos e vulnerabilidades envolvendo os jovens. As reportagens serviram de ponto de partida para as "rodas de conversas" com jovens de diferentes segmentos sociais. O objetivo da pesquisa foi investigar o modo como os jovens vivenciam a violência e explicitam a compreensão do risco e da vulnerabilidade a que estão expostos. Esta pesquisa, ao incentivar a reflexão sobre o modo como a violência urbana e a vulnerabilidade afetam a experiência subjetiva da juventude, oferece subsídios para a criação de projetos intervencionistas de caráter preventivo.

Palavras-chave: juventude; violencia urbana; vulnerabilidade; subjetividade; morte.

\section{VIOLENCE AND VULNERABILITIES: THE YOUNG AND DAILY NEWSPAPER'S NEWS}

\begin{abstract}
In Brazil, approximately $56 \%$, that is, more of the half of the victims of the total of homicides committed have between 15 and 29 years of age. The research started by gathering and collecting newspapers' news regarding death situations as well as those of vulnerabilities concerning the young. The reports served as starting points to "debate sessions" with young people from various social segments. The aim of the research was to investigate in which ways young people live under violence and express their understanding of the risks and vulnerability to which they are exposed. This research, as it instigates reflection on how urban violence and vulnerability affect the subjective experience of the young, contributes to the creation of interventionist programs of preventive character.
\end{abstract}

Keywords: young; urban violence; vulnerability; subjectivity; death.

^ Mestre em Psicologia Clínica pela Pontifícia Universidade Católica do Rio de Janeiro. Endereço: Rua Marquês de S. Vicente, n $^{\circ} 225$ - Praça Alceu Amoroso Lima. Gávea - Rio de Janeiro - RJ. E-mail: carolina_salomao@yahoo.com.br

$\star \star$ Psicóloga. Doutora em Educação pela Pontifícia Universidade Católica do Rio de Janeiro. Endereço: Pontifícia Universidade Católica do Rio de Janeiro, Centro de Teologia e Ciências Humanas, Departamento de Psicologia. Rua Marquês de São Vicente, 225. Gávea. 22543-900 - Rio de Janeiro, RJ - Brasil.

E-mail: soljobim@puc-rio.br 


\section{INTRODUÇão}

A presente pesquisa teve como objetivo investigar o modo pelo qual os jovens vivenciam a experiência da violência e do risco, tendo como fio condutor as seguintes indagações: (i) qual o impacto nos jovens da convivência indistinta com a morte imposta pela violência urbana? (ii) que tipo de experiência subjetiva em relação à própria morte, a proximidade com a morte do outro desencadeia? (iii) qual a possibilidade que os jovens têm de planejar o futuro, inseridos numa realidade que questiona o porvir a partir da frequente incidência de morte prematura?

Para responder a essas questões desenvolveu-se uma metodologia que teve como principal foco a escuta dos jovens - protagonistas da problemática - e a representação que essa faixa etária constrói acerca da própria realidade.

A pesquisa propriamente dita aconteceu em três etapas de campo e análise. Num primeiro momento, realizamos a coleta e arquivamento de notícias de jornal. O jornal revelou-se um suporte essencial, pois, através das notícias circunstanciadas em fatos reais, trouxe uma maior concretude ao tema, em geral mais conhecido apenas com base em estatísticas. Entre os meses de maio de 2008 a janeiro de 2009 foram pesquisadas e selecionadas, do jornal $O$ Globo, notícias referentes a situações de risco, vulnerabilidade e óbito envolvendo jovens no Brasil. Nessa investigação, tendo por base um jornal de grande circulação, buscou-se uma aproximação com o modo como os discursos jornalísticos representam a violência e a vulnerabilidade da juventude brasileira, ou seja, os modos como estes fenômenos se expressam e são disseminados no campo social.

Concomitante à coleta e ao arquivamento das notícias de jornal, uma pesquisa teórica foi desenvolvida, tendo como propósito definir o conceito de "vulnerabilidade", uma vez que consideramos ser este um conceito central para compreendermos a vivência cotidiana da juventude com o risco e a morte. Essa investigação sobre o termo levou-nos à divisão do conceito de "vulnerabilidade" em três categorias, que serão discutidas posteriormente neste texto: individual, social e institucional.

$\mathrm{Na}$ terceira etapa da pesquisa, as notícias coletadas serviram de material para reflexão, no contexto da realização de oficinas com jovens de diferentes segmentos sociais, promovendo um debate sobre as múltiplas faces da vulnerabilidade, evidenciando como os jovens reconhecem ou ignoram a realidade demonstrada pelas notícias. A partir dos resultados desta pesquisa foi produzido um vídeo documentário, intitulado "Próxima Parada: Juventude", ${ }^{2}$ com o objetivo de ampliar as estratégias de interlocução, não apenas com os jovens protagonistas dos depoimentos, mas também com outros jovens desta faixa etária que vivem em contextos sociais diversos e com profissionais que atuam diretamente com políticas públicas voltadas para minimizar questões relativas aos problemas da violência urbana. Vale dizer que, nesta pesquisa, não houve nenhuma pretensão de anonimato, pois todos os participantes concordaram em dar seus depoimentos no âmbito das oficinas denominadas "rodas de conversas", expondo seu rosto e suas ideias de frente para uma câmera de vídeo, conscientes de que seus de- 
poimentos iriam servir de base para a realização de um vídeo documentário. Em síntese, nosso objetivo com esta pesquisa foi criar estratégias metodológicas que pudessem incentivar a reflexão crítica de diferentes segmentos da sociedade envolvidos com políticas públicas e projetos sociais voltados para a juventude, sobre o modo como os jovens vivenciam a violência urbana e explicitam a compreensão do risco e da vulnerabilidade a que estão expostos.

\section{VIOLÊNCIA E VULNERABILIDADE DAS POPULAÇÕES JOVENS NOS CENTROS URBANOS}

A relação entre juventude e violência na sociedade brasileira contemporânea pode ser examinada mediante a recorrência a várias fontes de dados. Órgãos oficiais, como a Organização das Nações Unidas para a Educação, a Ciência e a Cultura (Unesco), e pesquisas universitárias, como as desenvolvidas pelo Laboratório da Violência da Universidade Estadual do Rio de Janeiro (LAV-UERJ), são exemplos de fontes atuais e confiáveis acerca do tema.

Segundo dados da Unesco, as taxas de mortalidade mais elevadas por causas externas (óbitos por violência conjunta decorrentes de homicídios, suicídios, agressões e acidentes de trânsito) estão no grupo com idade entre 15 e 24 anos. Deste modo, a juventude, exposta a violências externas, fruto da desigualdade socioeconômica, ou inserida em uma realidade permeada por riscos impostos ou autoinfligidos, configura-se como um período da vida de extrema vulnerabilidade.

Se dividirmos a população em dois grandes grupos, os jovens, de 15 a 24 anos, e os "não-jovens", de 0 a 15 e 25 e mais anos, teremos na população "nãojovem" $9,8 \%$ de mortes atribuíveis a causas externas, enquanto entre os jovens as causas externas são responsáveis por $72 \%$.

Essas estatísticas encontram-se no relatório "Mapa da Violência" da Unesco, principal fonte de dados e informações sobre o tema. Publicado bienalmente, o estudo traz os índices mais recentes sobre a violência nos âmbitos nacionais e internacionais e seus efeitos potencializados na população jovem. Em seu último Mapa (WAISELFISZ, 2005), o estudo traçou comparações internacionais realizadas em 67 países e evidenciou que o Brasil ocupa o quarto lugar nas taxas de homicídio no que se refere à população em geral, e o quinto, na sua população jovem. O primeiro lugar é ocupado pela Colômbia, país onde o tráfico também é o principal aliciador da criminalidade, mas em algumas cidades brasileiras, como Maceió e Recife, as taxas de mortalidade superam as colombianas. A América Latina é o continente mais vulnerável, tendo Colômbia, Venezuela, El Salvador e Brasil como os principais representantes. Para se ter uma ideia da discrepância das taxas de mortalidade entre os continentes, comparado com o resto do mundo, o jovem latino-americano tem 30 vezes mais chances de ser vítima de homicídio do que um jovem europeu. 


\section{O JORNAL: COMENTADOR DO COTIDIANO}

Inicialmente, apresentaremos alguns argumentos teóricos que nos orientaram na escolha do jornal como um objeto de pesquisa, com diferentes funções, mas especialmente como instrumento para o desenvolvimento da pesquisa de campo a partir de oficinas com jovens, caracterizadas como rodas de conversas. Nesta perspectiva, a respeito da utilização do jornal como estratégia metodológica, Spink (2006) afirma que os jornais fazem parte das múltiplas práticas do cotidiano e, portanto, oferecem pistas para a reflexão das realidades neles apresentadas. Nessa pesquisa, o jornal foi essencial para ilustrar e confirmar uma realidade muito presente, porém conhecida muitas vezes apenas a partir de dados e estatísticas.

A hipótese é que, se é possível dar pouca atenção às estatísticas acerca da situação da juventude na contemporaneidade, é praticamente impossível não perceber sua frequente presença nos meios de comunicação. É razoável desconhecer quais os municípios mais ou menos violentos para essa faixa etária, mas é improvável não perceber a vitimização dos jovens nas editorias dedicadas à cidade e ao país.

Entre os meses de maio de 2008 e janeiro de 2009 foram coletadas aproximadamente 230 notícias protagonizadas por jovens em situações de risco e violência. O levantamento desses dados foi feito no jornal $O$ Globo. Este veículo impresso foi escolhido por tratar-se de um jornal de grande circulação e abrangência de assuntos, com seções como "Rio" e "O País" dedicadas, respectivamente, a acontecimentos da cidade e do estado do Rio de Janeiro e do país.

O processo de coleta das notícias se dava diariamente. Com frequência, havia notícias sobre o tema na capa; entretanto, majoritariamente, as editorias habituais eram "Rio" e "O País". A coleta das notícias não se restringiu a nenhuma seção específica - abrangendo, portanto, matérias de cadernos dirigidos aos jovens e às seções gerais do jornal. Entretanto, a maior incidência de notícias, com foco na violência e na condição de vulnerabilidade, concentrara-se nessas últimas. As notícias iam sendo recortadas, digitalizadas e armazenadas em pastas para posterior análise.

A partir da análise dos conteúdos e das conclusões iniciais, percebeu-se a necessidade de buscar uma conceituação para o termo vulnerabilidade, pois este se configurou como central para a análise do problema da violência no contexto das populações jovens. Ainda que todas as notícias tratassem do mesmo tema, ficou evidente que as especificidades de contextos sociais e culturais e situações não poderiam ser ignoradas, sendo elemento fundamental para uma conceituação mais precisa do conceito de vulnerabilidade e risco. A heterogeneidade das notícias forneceu a pista da pluralidade do conceito. Embora o critério da coleta tenha sido a presença do jovem nas notícias relacionadas à condição de vulnerabilidade e violência urbana, o que se constatou foi que, em alguns grupos de notícias, essa era a única coisa em comum entre elas. 


\section{VULNERABILIDADES: SOCIAL, INSTITUCIONAL E INDIVIDUAL}

\section{Vulnerabilidade social}

Os primeiros trabalhos ancorados na perspectiva da vulnerabilidade social foram desenvolvidos motivados pela preocupação de abordar de forma mais integral e completa não somente o fenômeno da pobreza, mas também as diversas modalidades de desvantagens sociais. Assim, essa categoria de vulnerabilidade diz respeito à própria estrutura da sociedade, de direitos e acessos desiguais.

Adorno (2001, p.11) explica:

Mais usualmente utilizada em nossos dias pelos movimentos sociais e de direitos humanos, a expressão vulnerabilidade social sintetiza a idéia de uma maior exposição e sensibilidade de um indivíduo ou de um grupo aos problemas enfrentados na sociedade e reflete uma nova maneira de olhar e de entender os comportamentos de pessoas e grupos específicos e sua relação e dificuldades de acesso a serviços sociais como saúde, escola e justiça.

A notícia "Boletim da violência" exemplifica o estado de vulnerabilidade social a que estão submetidos moradores de comunidades violentas do Rio de Janeiro. A reportagem informa que, das dez escolas de pior desempenho no Índice de Desenvolvimento da Educação Básica (Ideb) na rede municipal de ensino do Rio, nove estão localizadas em áreas violentas da cidade. Essa notícia exemplifica uma das facetas dessa categoria de vulnerabilidade.

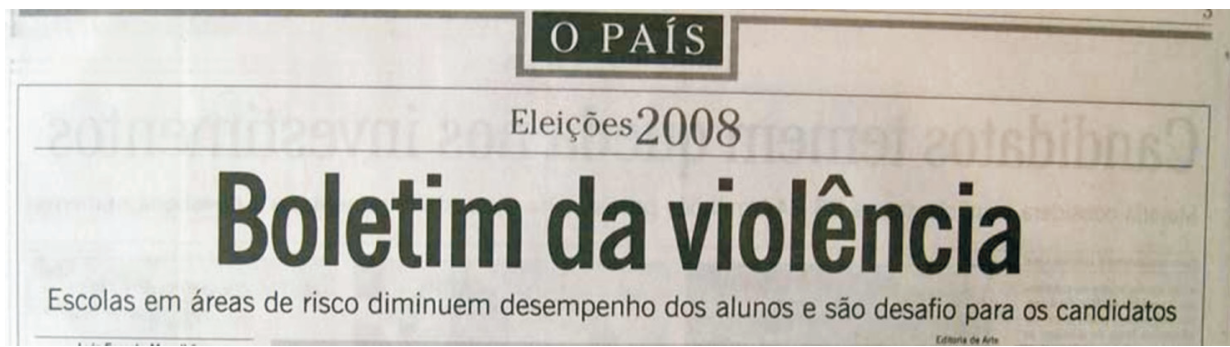

O Globo/Rio 3 - 22/09/08

Vignoli (apud ABRAMOVAY et al., 2002, p. 30) comenta que a condição de vulnerabilidade social constitui-se a partir da interação de diferentes componentes - tais como posse e controle de recursos materiais e estruturas de oportunidades provindas da sociedade e do Estado - e refere-se à situação em que o conjunto de características, recursos e habilidades inerentes a um grupo social, se revelam insuficientes, inadequados ou difíceis para lidar com o sistema de oportunidades oferecido pela sociedade, de forma a ascender a maiores níveis de bem-estar ou diminuir probabilidades de deterioração das condições de vida de determinados atores sociais. 
É grande o reconhecimento, entre pesquisadores e autoridades governamentais, de que os jovens constituem hoje uma parcela da população particularmente vulnerável aos problemas sociais e econômicos no país. Na América Latina, indicadores como o Programa das Nações Unidas para o Desenvolvimento (PNUD) e o Relatório do Desenvolvimento Humano (RDH), evidenciam que a juventude ainda está sujeita a sérias limitações relacionadas a direitos básicos, tais como o acesso ao conhecimento disponível e adequado às modernas necessidades sociais, o acesso ao mercado de trabalho e ao direito a uma vida longa e saudável.

Assim, o conceito de vulnerabilidade social se articula com a percepção de que o local de moradia e as condições de vida da família podem ser fatores de dificuldade, de obstáculo na realização dos projetos pessoais do jovem, ao mesmo tempo em que favorecem estilos de vida e de integração social que podem adicionar riscos à sua trajetória.

\section{Vulnerabilidade institucional}

Semelhante à definição dada pela Unesco, vulnerabilidade institucional diz respeito às limitações e incapacidade de o Estado fornecer igualitariamente insumos fundamentais para o desenvolvimento dos recursos materiais e simbólicos. No entanto, esse conceito vai além, ao reconhecer, na omissão do poder público, um fator agravante de riscos e vulnerabilidades, quando não é o próprio causador.

A matéria de capa, "Decretada prisão de militares", ilustra claramente a subversão do papel da segurança pública. Diz a reportagem:

Os militares ocuparam o Morro da Providência em dezembro de 2007 com o objetivo de acompanhar as obras de reforma de 780 casas, conforme projeto apresentado pelo senador Marcelo Crivella. Apesar dos oficiais terem dito que a missão era apenas social, não faltaram críticas as ações da corporação, assim como denúncias de conluio entre militares e traficantes.

Na madrugada do dia 16 de julho de 2008 a Justiça decretou a prisão temporária de 11 militares do Exército acusados de homicídio de três jovens detidos dias antes no Morro da Providência. Os militares foram acusados de terem vendido os rapazes aos traficantes do Morro da Mineira, que é comandado por uma facção rival. Os corpos dos jovens foram encontrados no domingo em um aterro sanitário.

No caso relatado no jornal, o Estado - representado pelo Exército - não só falha no dever de assegurar a segurança à comunidade, como agencia uma barbárie que, naturalmente, deveria combater.

\section{Decretada prisão de militares}

Onze integrantes do Exército sāo acusados do homicídio de três jovens 'vendidos' a traficantes

Rio $8-16 / 06 / 08$ 
Cada vez mais, além de falhar em seu papel de oferecer segurança a toda população, frequentemente o Estado tem sido promotor de violências sem precedentes. Diferentes autores ressaltam que "o crescimento do crime e da violência resulta não apenas da pobreza e da desigualdade social. Resulta também da incerteza política e dos conflitos institucionais" (MESQUITA NETO et al., 2001, p. 34).

Nos jornais, um exemplo dessas iniquidades citadas pelo autor são as notícias que trazem a associação da polícia com o crime organizado e a expansão da atuação de milícias - grupos constituídos por polícias militares, ex-policiais e políticos - em comunidades antes agenciadas pelo tráfico de drogas. Nesses casos, as milícias chegam às favelas com o marketing da moralidade, prometendo combater o tráfico, aproveitando a lacuna deixada pelo Estado.

Isso posto, podemos afirmar que a vulnerabilidade institucional vai além da incapacidade do Estado em cumprir sua função básica de garantir segurança e bem-estar. Esse aspecto da vulnerabilidade mostra que, em diversos casos, o poder público é promotor da violência que deveria combater.

\section{Vulnerabilidade individual}

Os jovens, por suas características biológicas e psíquicas, necessitam identificar-se com um mundo que lhes ofereça suporte emocional para enfrentarem e desfrutarem essa fase da vida, repleta de inseguranças e conflitos internos. Essas características, aliadas à falta de perspectivas originadas pelas discrepâncias sócioeconômicas e culturais, são fatores precipitantes da exacerbação de comportamentos violentos e condutas de risco, desencadeantes dos homicídios, inscritos na vulnerabilidade individual (SANT'ANNA, 2005, p. 121).

Para Lipovetsky (LIPOVETSKY; CHARLES, 2004), modos de vida irresponsáveis, comportamentos compulsivos, excessos de toda ordem, violência gratuita e toxicomanias são frutos nocivos da hipermodernidade. Ainda segundo o autor, o hedonismo individual, fomentado pela lógica individualista e a cultura do consumo comum ao nosso tempo, favorece um relativismo desenfreado de valores, permitindo o livre curso de toda sorte de elucubrações e de ações possíveis. Os jovens formam um grupo especialmente atingido por essa lógica reinante. É comum, em seus discursos, e ações a exteriorização dos sentimentos de urgência, angústia, ousadia associada à revolta, desassossego e não pertencimento. A busca pelo risco surge como meio de despressurização dessas sensações.

Deste modo, a possibilidade de morte é evidente e está implícita em todo comportamento de risco, mas, aparentemente, não é isso que tal comportamento quer evocar. Nesse sentido, abuso de álcool, excessos de drogas ilegais, promiscuidade sexual, direção imprudente, são, antes de tudo, formas de reivindicação de um olhar sobre a realidade de vida do jovem, solicitando uma visibilidade para a falta de sentido dos projetos de vida. 
Assim, trata-se, também, de compreender o sentido social do risco em suas dimensões objetivas e subjetivas, ou seja, o papel que as situações de risco e modo de enfrentá-las têm no processo de formação identitária. As situações de vulnerabilidade surgem quando diante do risco, ocorre uma cisão no processo de formação identitária que pode resultar na adoção do risco como parte da identidade ou do processo de sua formação (PERES, 2007, p.138).

Vulnerabilidade é, portanto, conceito que pede recorrência a diversas unidades de análise - indivíduos, domicílios e comunidades -, além de se recomendar que identifiquem cenários e contextos. Pede, portanto, olhares para múltiplos planos e, em particular, para estruturas sociais vulnerabilizantes ou condicionamentos de vulnerabilidades (CASTRO; ABRAMOVAY, 2005, p. 55).

Cabe ressaltar que as categorias de vulnerabilidade estabelecidas e definidas na pesquisa têm como propósito auxiliar a compreensão da pluralidade do termo e especificar âmbitos e panoramas. Não há, entretanto, intenção ou mesmo interesse de "engessar" a realidade pesquisada em divisões e conceitos que possam restringir o olhar para a questão. É evidente que, embora seja possível perceber diferenças entre os contextos de violência e vulnerabilidade, fica claro também que essas realidades se perpassam e dialogam constantemente.

\section{Percursos da Pesquisa de CAMPo: O uso das notícias nas ${ }^{66}$ Rodas de CONVERSAS"}

As "rodas de conversa" tiveram como proposta convidar os participantes a debater o tema da violência e vulnerabilidade, tendo como mote os recortes de notícias selecionadas de um total aproximado de 230 notícias, coletadas do jornal $O$ Globo ao longo de um período de nove meses. A intenção do recorte foi buscar, dentro do número total de notícias coletadas, reportagens que representassem os três tipos de vulnerabilidade estabelecidos anteriormente: "social, institucional e individual". Como veremos a seguir, sete reportagens foram selecionadas e utilizadas para fomentar o debate nas "rodas de conversas".

As notícias selecionadas para o debate nas "rodas de conversas" foram as seguintes: 


\begin{tabular}{|c|c|c|c|}
\hline Data & Editoria & Notícia & \begin{tabular}{|c|} 
Tipos de \\
Vulnerabilidade
\end{tabular} \\
\hline $27 / 05 / 08$ & Rio 11 & $\begin{array}{l}\text { Acidentes: 1/3 das vítimas é jovem } \\
\text { segundo Detran, de } 22 \text { mil acidentados, no ano passado, } 7,6 \text { mil tinham até } 29 \text { anos }\end{array}$ & Individual \\
\hline $02 / 06 / 08$ & Rio 9 & 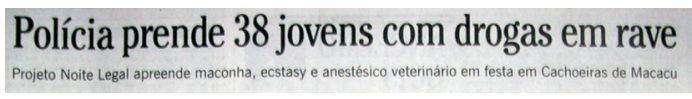 & Individual \\
\hline $16 / 06 / 08$ & Сара & $\begin{array}{c}\text { Militares são } \\
\text { presos por } \\
\text { entregar jovens } \\
\text { para } 0 \text { tráfico } \\
\text { Delegado acusa } 11 \text { homens pela } \\
\text { morte de moradores da Providência }\end{array}$ & Institucional \\
\hline $29 / 06 / 08$ & Rio 24 & 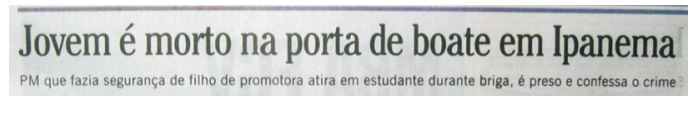 & Institucional \\
\hline $15 / 07 / 08$ & O País 9 & $\begin{array}{l}\text { Morte de jovens por PMs causa revolta } \\
\text { Governador do Parana classifica açäo de injustificíavel ediz que policiais seráo punidos }\end{array}$ & Institucional \\
\hline $15 / 09 / 08$ & Rio 11 & $\begin{array}{l}\text { Morre jovem } \\
\text { baleado em festa } \\
\text { em São Gonçalo } \\
\text { Estudante de } 17 \text { anos } \\
\text { ficou sete dias em } \\
\text { coma; PM é suspeito }\end{array}$ & Social \\
\hline $23 / 12 / 08$ & O País 4 & $\begin{array}{l}\text { Morte no navio: Isabella bebeu demais } \\
\text { e foi asfixiada pelo vômito, diz a PF } \\
\text { segundo delegado, pimeiros depoimentos não confirmam consumo de drogas }\end{array}$ & Individual \\
\hline
\end{tabular}


Foram realizadas, no período de maio a agosto de 2009, três oficinas, aqui caracterizadas como "rodas de conversa", a partir das notícias apresentadas aos jovens. A primeira aconteceu na Universidade Estadual do Rio de Janeiro, com estudantes do curso de Pedagogia; a segunda, na Pontifícia Universidade Católica do Rio de Janeiro, com estudantes do curso de Psicologia e a terceira, em um núcleo do Pró-Jovem, ${ }^{4}$ no município de Belford Roxo. ${ }^{5}$ Cada encontro teve uma duração média de 1 hora e 30 minutos e contou com a participação de dez jovens. Embora as "rodas de conversa" tenham sido realizadas em espaços distintos, no processo de transcrição das falas e organização dos depoimentos deflagrados a partir das notícias do jornal privilegiamos o encontro e confronto das diferentes vozes, sem uma preocupação em explicitar os discursos dos jovens a partir do lugar social que ocupam.

A partir da leitura das notícias nas "rodas de conversas" duas questões foram colocadas para incentivar o debate entre os jovens e as pesquisadoras, a saber: por que os jovens morrem? como eles morrem?

Pôde ser constatado que, na fala dos jovens durante as oficinas, as categorias de vulnerabilidade e risco, extraídas das notícias de jornal, ganharam maior concretude à medida que eram atualizadas a partir de relatos contundentes de histórias de vida e experiências dos próprios jovens. Assim, a análise dos depoimentos dos jovens possibilitou instituir novas categorias de vulnerabilidade, mais específicas e concretas referendadas pela experiência narrada dos participantes. ${ }^{6}$

\section{Com a PALAVRa OS JOVENS}

Neste segmento articulamos as falas dos jovens com reflexões de autores que analisam o tema da violência urbana e juventude. As categorias de vulnerabilidades mais amplas, definidas no início da pesquisa, se reapresentaram na fala dos jovens. Seus depoimentos conferiram especificidades para as divisões do termo. Situações de vulnerabilidade social, individual e institucional emergiram nas experiências pessoais citadas pelos jovens participantes. Assim, a partir dos depoimentos, foi possível extrair subcategorias mais específicas, caracterizadas e definidas pela experiência narrada dos jovens. As subcategorias revelam como os jovens compreendem a condição de vulnerabilidade em que se encontram. Selecionamos das falas dos jovens quatro temas que se mostraram recorrentes, e que serão apresentados a seguir:

\section{COMPORTAMENTOS IRRESPONSÁVEIS APRESENTADOS COMO TÍPICO DOS JOVENS}

O conceito de vulnerabilidade individual está intimamente relacionado às características da contemporaneidade. Diversos autores (KEHL, 2004; BAUMAN, 1998; EHRENBERG, 2000) apresentam nossos dias como tempos de urgência, de fluidez dos laços afetivos, comportamentos compulsivos, excessos de demandas e possibilidades. Essas características foram explicitadas nos relatos trazidos pelos jovens. A partir das notícias que representavam essa categoria mais ampla de vulnerabilidade, os jovens revelaram uma visão negativa da juventude. 
A reportagem "Acidentes: $1 \backslash 3$ das vítimas é jovem" apresentava um levantamento realizado pelo Detran, no qual, das 22.502 vítimas de trânsito - entre mortes e feridos - que tiveram a idade identificada, 7.617 delas (cerca de $33 \%$ ) eram homens e mulheres entre 18 e 29 anos. A reportagem é ilustrada pela foto do enterro de quatro jovens mortos em um acidente de trânsito recente. Segundo a reportagem, os jovens colidiram com um poste após sair de uma casa de show. A notícia trouxe à tona o discurso da imprudência e da irresponsabilidade como comportamento típico da juventude.

Embora, a reportagem não explicite o uso de álcool no acidente noticiado, Ariadine, ${ }^{7}$ uma das jovens participantes da pesquisa, supõe que os jovens envolvidos no acidente estavam alcoolizados. Ela defende seu argumento citando experiências próprias.

Eu saio, vou para essas baladas também e não tem essa de tô bebendo não vou dirigir, acaba rolando, dirige sim não tem responsabilidade com a própria vida nem com as que estão dentro do carro [...] eu acredito que esses jovens morreram por imprudência, pelo fato de voltarem de madrugada de uma casa de festa, na certa eles deviam estar sob efeito de álcool, perderam o controle do carro, bateram em um poste e morreram os quatro (Ariadine).

A reportagem "Morte no navio: Isabella bebeu demais e foi asfixiada pelo vômito, diz a PF" trata da morte de uma menina de 20 anos que morreu em um cruzeiro universitário. $\mathrm{O}$ recorte traz ainda relatos de outros jovens que estavam no navio e o depoimento de um dos integrantes da tripulação. Na declaração, o funcionário não identificado relata o comportamento dos jovens, expõe os excessos com bebidas e a promiscuidade no sexo. A respeito da notícia, Graziela comenta:

Graziela - Os jovens hoje em dia acham que felicidade e curtição estão nisso: "ah, eu vou beber porque aí eu to feliz", "vou me drogar porque a vida é uma festa" e eu acho que não é assim, eu acho que tem muitas coisas para se fazer na vida que dá mesmo emoção que uma droga dá, que um ecstasy dá e eu acho que isso é vida jogada fora.

Juliana - Os jovens fazem as coisas sem pensar no depois, o que interessa é o agora, eles nunca pensam nas consequências do ato, apenas no prazer do momento, por exemplo, esses jovens do barco estavam dormindo com qualquer um, bebendo muito, destruindo tudo, se drogando mesmo.

A relação com o tempo foi questão na fala de outros jovens. Em muitos depoimentos o jovem foi retratado como imediatista. Pressa e urgência foram termos utilizados para descrever a relação do jovem com o tempo. No entanto, houve considerações sobre o futuro. Ironicamente, com frequência a juventude é vista como um momento de transitoriedade no qual o jovem é incompleto, tendo 
no futuro, na passagem para a vida adulta, o sentido das suas ações no presente. Nesse sentido, Dayrell (2007) destaca que essa perspectiva esconde uma tendência de encarar a juventude, "o que não chegou a ser", negando o presente vivido.

Podemos concluir que existe um conflito de visões: se, na teoria, o presente é desvalorizado, na fala de alguns jovens sobre outros este parece ser o único tempo que existe. Entretanto, não existe soberania de verdades. Em outra fala, Juliana destaca sua preocupação com o futuro, trazendo à tona a relevância, a ansiedade e as inquietações em relação ao porvir.

Juliana - Hoje nós estamos vivendo essa violência toda e amanhã, o que nós vamos viver? A gente tem que pensar sempre no futuro, não é no presente não, porque o presente nós já estamos, o passado já foi. A gente tem que pensar sempre lá na frente.

Em outro depoimento, a participante demonstrou uma preocupação com a transmissão de valores desses jovens que um dia serão pais. A jovem destaca que as ações do presente podem acarretar consequências graves no futuro e lembra $o$ compromisso dos jovens com sua própria geração.

Juliana $-[\ldots]$ Os jovens de amanhã serão pais de outros jovens. E que tipo de exemplo que eles poderão dar? Então eu acho que as pessoas têm que pensar muito no que elas fazem hoje porque amanhã podem trazer consequências gravíssimas para a vida delas. Então o que tá faltando realmente, é todo mundo parar e pensar em tudo que tá fazendo e tentar ver o que pode fazer para de fato ser a diferença, nesse mundo, nessa geração. E que venha impactar essa geração de uma forma boa, de uma forma que venha mostrar que fazer a coisa certa é bom e não ficar mostrando apenas as coisas ruins.

Em outro grupo encontramos opinião semelhante. Ambos os depoimentos clamam por atitudes responsáveis e consequentes por parte dos jovens.

Cilaine -É eu acho que falta consciência mesmo. E eu tenho isso para minha vida: o que a gente planta a gente vai colher. A maioria aqui tem filhos e os que não têm vão ter um dia, e tem também a questão do exemplo: do cidadão honesto, do cidadão de bem, então tem que procurar educar da melhor forma possível para que a criança se torne um adolescente e um adulto com mais consciência, com responsabilidade, com honestidade.

Em muitas falas os jovens foram representados como irresponsáveis e inconsequentes. Contudo, as acusações vieram sempre acompanhadas de justificativas: desamparo ou cumplicidade por parte dos pais, ausência de referências e modelos de boa conduta na própria sociedade e pressões sociais de conduta e performances foram citados como vetores das atitudes dos jovens. 
No entanto, houve depoimentos críticos que se confrontam com a visão de que o jovem é naturalmente uma fonte de problemas. Em uma das "rodas de conversas", Eliane fala da possibilidade de o jovem ocupar um papel transformador na sociedade.

Eliane - Eu acho que o jovem é sempre visto como um problema, só o fato de você ser jovem, para sociedade você é um problema, você é perigoso. E, eu acho que, só pelo fato da gente tá aqui discutindo, cada um tem uma história. Ela diz: eu não faço isso, cada um tem o exemplo de uma pessoa que não faz. Então eu acho que a gente tem que tentar mudar isso, tem que tentar mudar a forma como o jovem é visto, e cabe a cada um fazer a sua parte. Uma andorinha só não faz verão, não faz. Mas, eu posso contagiar quem tá do meu lado e formar um grupo consistente. [...] Eu acho que tem que mudar essa visão, jovem não é um problema, ele pode sim se tornar um problema se não for bem orientado, se ele não tiver um aparato, sabe? Uma pessoa que olhe, que oriente, que converse.

No artigo "Juventude Brasileira, entre a tradição e a modernidade", Gonçalves (2005) faz uma crítica que é também uma contestação sobre o modo como os jovens são vistos e representados na sociedade contemporânea. Lembra a autora que, com frequência, a discussão surge contaminada por verdades canônicas referentes a crises e excessos.

A juventude, na visão clássica, é entendida como "uma categoria social gerada pelas tensões inerentes à crise do sistema" (Foraccchi, 1972, p. 160); estudos contemporâneos reafirmam seus excessos pulsionais (cf. Souza, 2005) como motores da construção das formas pelas quais o jovem se apresenta à sociedade. A primeira visão acentua o conflito e a busca pela experimentação; a segunda encaminha a postura individualista e narcísica, considerada típica da sociedade e da juventude contemporâneas (GONÇALVES, 2005, p. 207).

Através de uma pequena revisão histórica, a autora retoma a gênese da abordagem da questão. Na turbulenta Chicago dos anos 1920, jovens irlandeses, italianos, afro-americanos e judeus tornaram-se objeto de estudo da sociologia que buscava investigar a possível relação entre juventude, violência e desordem social. A guerra entre gangues na década de 1920 e a explosão demográfica nas cidades em 1950 contribuíram para o olhar negativo lançado aos estudos sobre a juventude. A partir daí, excessos e comportamentos disfuncionais tornaram-se alvos de programas de controle e prevenção.

Firmou-se no imaginário social a associação entre a juventude e as grandes questões de cada tempo: no século $\mathrm{XXI}$, quando grassam as preocupações com o individualismo exacerbado e a criminalidade crescente, o jovem emerge como individualista e responsável, em grande parte, pela criminalidade urbana (GONÇALVES, 2005, p. 208). 
Contudo, em consonância com o depoimento da jovem Eliane, a autora não concorda que a juventude - em toda a sua multiplicidade de vivências e organização - possa ser reduzida à hegemonia de pontos de vista ligados a desordem e criminalidade, frutos de uma natureza narcísica e individualista.

Seguindo a mesma linha crítica ao determinismo, em "Considerações sobre a tematização social da juventude no Brasil", Helena Abramo (2007) concorda que, embora muito se fale sobre os jovens, poucos são os estudos voltados para a consideração dos próprios jovens e suas experiências, suas percepções, formas de sociabilidade e atuação. A autora inicia o artigo fazendo uma breve revisão de como a juventude foi sendo representada ao longo das décadas, e de que modo. Segundo a autora, o que ocorre é que a juventude é sempre tematizada pela geração que a antecede e, deste modo, está sempre sujeita a comparações e julgamentos segundo referenciais do passado. A geração de 1980 foi julgada apática, individualista, consumista e indiferente pois a ela foi traçado um paralelo com os jovens da década de 1960. Isso não significa dizer que os adjetivos empregados para defini-la são falsos e que parte das suposições não se concretize. No entanto, as sucessivas comparações tornam a juventude presente sempre deficitária de um traço ou característica, seja positivo ou não. A crítica da autora é que pouca chance é dada para que o jovem do presente fale de si mesmo.

E nessa formulação, como encarnação de impossibilidades, eles nunca podem ser vistos, ouvidos e entendidos como sujeitos que apresentam suas próprias questões, para além dos medos e esperanças dos outros. Permanecem, assim, na verdade, semi-invisíveis, apesar da sempre crescente visibilidade que a juventude tem alcançado na nossa sociedade, principalmente no interior dos meios de comunicação (ABRAMO, 2007. p. 84).

\section{Desamparo familiar}

As múltiplas modalidades de desvantagens sociais que caracterizam a vulnerabilidade social se concretizaram nas situações vividas por grande parte dos jovens. Limitações relacionadas a direitos básicos, como saúde e educação, dificuldades de inserção no mercado de trabalho e desamparo familiar, foram exemplos mencionados.

A respeito da participação familiar nas questões referentes aos problemas da juventude, Eliane denunciou que existe muita negligência e omissão por parte dos pais. Referindo à notícia "Isabella bebeu demais e foi asfixiada pelo vômito, diz PF", a jovem argumenta:

Eliane - A Isabella é uma menina de 20 anos, se ela tivesse todo um apoio psicológico por parte dos pais, uma abertura, talvez uma conversa, não sei [... ] Acho que isso poderia ter sido evitado, não só o problema dela, mas da grande maioria dos jovens em situação semelhante [...] os pais precisam dialogar mais com os filhos e não impor, orientar. 
A falta de diálogo trazida pela jovem encontrou ressonância na fala de outras colegas. A incomunicabilidade entre pais e filhos foi questão recorrente. Segundo relato de Juliana, a falta de tempo e a crença de que bens materiais suprem a falta de afeto têm contribuído para o enfraquecimento da relação.

Juliana - Eu tenho conversado com várias pessoas, por vários motivos, e quase todas as pessoas com quem eu tenho conversado estão com problemas sérios pessoais, mas só que dentro de casa não encontram o apoio. O pai e a mãe estão dispostos apenas a ficar recriminando, julgando, não estão dispostos a parar cinco minutinhos para tentar descobrir como é que o filho está. E muitas vezes o adolescente se sente muito sozinho muito isolado. E muitas vezes eles acabam indo buscar respostas em pessoas que não podem trazer uma resposta convincente. Então a família tem sido muito omissa. Ela quase não tem aparecido, ela tem estado em segundo plano. Em primeiro lugar estão sempre o namorado ou a namorada, ou então os amigos. E o pai e mãe que, na minha opinião, deveriam ser os referenciais principais estão parecendo figurantes na vida dos jovens. Porque eles trabalham o dia inteiro para ficar comprando tudo que os filhos querem, mas nunca param para ver o que os filhos precisam e que muitas vezes não são coisas materiais e sim coisas como: uma conversa ou simplesmente um abraço. Eu sinto que está fazendo falta. Porque os jovens ultimamente estão muito tristes, muito deprimidos.

De acordo com Kehl (2004), muitos pais não servem de referência porque os próprios estão desprovidos de referenciais. O imperativo da juventude destituiu o adulto do lugar daquele que sabe. Nesse sentido, "a rede de proteção imaginária constituída pelo que o Outro sabe se desfaz, e a própria experiência perde significação" (KEHL, 2004, p. 97). A autora ressalta que a gradativa desvalorização da experiência descarta o passado em favor de uma eterna juventude e esvazia de sentido a própria vida. A tristeza e a depressão são deflagradas quando "em busca de perspectivas para o futuro os jovens olham para a vida dos mais velhos e encontram um espelho deformado de si mesmos" (KEHL, 2004, p. 97). Indaga a autora: como ingressar no mundo adulto onde nenhum adulto quer viver? Assim, a rebeldia dos jovens também estaria justificada na teoria da hegemonia do modelo jovem. A explicação, tomada da visão psicanalítica, esclarece que o imperativo do "mais prazer" ao que o jovem é impelido encontra-se desprovido dos limites e freios paternos para o excesso do que ele "quer" e "não quer" cometer. Deste modo, na ausência de interdição, o jovem, chegado à adolescência, responde com pânico e revolta o que, na verdade, é angústia.

A rebeldia dos adolescentes hoje parece antes um apelo a que os pais manifestem alguma forma de autoridade e façam restrição ao gozo. Não se trata da insatisfação de quem se sente aquém da liberdade e dos prazeres que gostaria de 
desfrutar, e sim da angústia de quem se vê diante da demanda de gozar ilimitadamente [...] (KEHL, 2004, p. 99)

Eliane e Juliana deixam claro em suas falas as consequências negativas da liberdade excessiva e falta de diálogo na relação entre pais e filhos. Ambas as jovens concordam que comunicação e carinho são elementos escassos na dinâmica familiar e Juliana destaca o papel coadjuvante dos pais na vida dos jovens.

Valdemar argumenta que o desamparo familiar não se expressa somente na ausência e pouca participação de pais e mães na formação dos filhos. Em alguns casos, o desamparo se apresenta revestido de cumplicidade e permissividade dos pais em relação às delinquências dos filhos.

Valdemar - Acho que o jovem tá muito irresponsável hoje em dia também por causa disso: ele apronta na rua, chega em casa o pai passa a mão na cabeça. E já que os pais passam a mão na cabeça tinha que haver punição para os dois [...] As autoridades ficam falando que os jovens são irresponsáveis. São sim, mas mais irresponsáveis são os pais que não estão ali olhando. Apareceu com o negócio em casa, tem que perguntar: - isso aqui é de quem? É da onde? Cê comprou isso aqui com que dinheiro? Hoje em dia não, o jovem sai, quando volta, volta com roupa de marca, tênis e os pais não procuram saber. Depois quando vai procurar saber (o filho) já tá preso, já aconteceu alguma coisa, já matou outra pessoa. Então acho que pai e mãe também devem ser punidos de uma determinada forma. Não só os filhos, os pais também.

Em "A juventude como sintoma da cultura", Maria Rita Kehl (2004) fala do prestígio que a condição de ser jovem adquiriu na contemporaneidade. Mais que uma etapa etária, "juventude é um estado de espírito, é um jeito de corpo, é um sinal de saúde e disposição, é um perfil do consumidor, é uma fatia do mercado onde todos querem se incluir" (KEHL, 2004, p. 89) A elasticidade do conceito chegou ao ponto de podermos afirmar que, dos 18 aos 40 anos, todos os adultos são jovens. Entretanto, esse prestígio é recente e em parte tributário da indústria cultural.

Vale destacar que em diversos depoimentos ouvimos opiniões que se afiliam com o pensamento da autora. Na fala dos jovens, essa irresponsabilidade é problematizada.

Graziela - Acho que os pais hoje estão muito jovens, os pais estão sendo influenciados pelos filhos. Hoje os pais estão permitindo aos filhos coisas que não eram permitidas há vinte anos, como dar carro na mão do filho, deixar os filhos fumarem. Antigamente, os pais fumavam, mas não deixavam os filhos fumarem. 
“A vaga de 'adulto', na nossa cultura, está desocupada" (KEHL, 2004, p. 96). Kehl explica a afirmação a partir do já mencionado declínio da autoridade da condição de adulto. Com seus saberes e experiências questionadas, os mais velhos sentem-se desconfortáveis com a responsabilidade de educar. A impopularidade da categoria adulto, visto agora como careta, dissipou o conflito de gerações, na medida em que ninguém quer ocupar o outro lado. Diz a autora que esta liberdade recai em desamparo. Vivendo em um mundo em que as regras parecem ser feitas por eles e para eles, os jovens atuam socialmente destituídos de referenciais e parâmetros, uma vez que pais e educadores estão empenhados em aparentar eles também juventude. ${ }^{8}$

\section{FALTA DE OPORTUNidAdES DE EMPREgo.}

Cecília enquanto mãe reconhece que é papel dos pais a formação moral dos filhos, mas argumenta que a falta de oportunidade de emprego leva os pais, que precisam sustentar seus filhos, a gestos desesperados.

Cecília-É falta de ensinamento dos pais? É sim, mas também eles não estão tendo chance. Os próprios pais não estão tendo chance. Não estão conseguindo emprego. Alguns conseguem e têm emprego, mas os que não conseguem têm que sustentar a família [...] hoje tá muito difícil e muitos apelam pelo lado mais fácil: drogas. E, às vezes estão fazendo os próprios filhos venderem as drogas.

Rodrigo - A questão não é só: ah, vou pular para a vida do crime porque lá é mais fácil e eu não quero trabalhar não. É porque hoje tá mais difícil trabalhar do que entrar para a vida do crime. Eu quero estudar, trabalhar, sou dona de casa, faço tudo direitinho, bato lá na porta atrás de emprego e não tem nada, fechado. Quer dizer: tá tudo mais difícil. Então onde ela vai procurar? Onde tá mais fácil. E onde tá mais fácil? No morro, nesses lugares errados, consequentemente não vai ser bom para você nem para o seu filho. Às vezes, as pessoas vão por necessidade, claro, tem gente que vai por maldade, coloca uma pistola na cintura e tá tirando a maior onda, mas tem gente que vai porque tem necessidade. E, às vezes, a questão não é porque o pai te ensinou errado, é porque o mundo hoje em dia, para trabalho, para estudo tá muito difícil. Então, tá muito mais fácil entrar para a vida do crime. Se o governo dá oportunidade para você estudar, por que não dá oportunidade de você mais na frente conseguir um emprego? Eu tenho estudo, mas as portas não se abrem, então eu vou para onde? Como eu vou sustentar minha família? Meu filho passou mal e eu não tenho dinheiro nem para o ônibus. O que eu vou fazer? Vou colocar um negócio na cintura e sair por aí. 
Soares, Bill e Athayde (2005) destacam a existência, Brasil afora, de uma cultura da violência, gestada, alimentada e reproduzida pelo tráfico de drogas, que a utiliza seja para recrutar jovens vulneráveis a seu apelo, seja para integrálos a seu sistema de trabalho e poder. Dizem os autores:

[...] Se o tráfico recruta, atrai, seduz, é porque traz benefícios. Os benefícios são as evidentes vantagens materiais, como dinheiro, acesso ao consumo, e são também os bens simbólicos e afetivos, como a sensação de importância e poder, o status, o sentimento de pertencimento a um dotado de identidade tudo isso significa valorização pessoal, reforço da auto-estima (SOARES, BILL, ATHAYDE, 2005, p. 285).

A solução melhor e mais realista, segundo os autores, para a redução da capacidade de recrutamento do tráfico, não está na tentativa de destruí-lo, mas sim de competir com ele, e para isso não bastam empregos ou frentes de trabalho. A demanda dos jovens é por superação da trajetória dos pais e, sobretudo, por cidadania.

Às vezes, qualquer emprego resolve, em geral não é assim que acontece. Os jovens não querem repetir a trajetória de fracasso dos pais. Eles não querem ser apenas pintores de nossas paredes, mecânicos de nossos carros, engraxates de nossos sapatos. Eles querem o que os nossos filhos querem: internet, música, arte, dança, esporte, cinema, mídia, tecnologia de última geração, criatividade. Já se foi o tempo em que bastava acenar com a integração subalterna para calar demandas. Agora, quem demanda quer mesmo a tal cidadania, que significa pleno acesso ao mundo dos direitos e a tudo o que nossa sociedade pode oferecer". (SOARES; BILL; ATHAYDE, 2005, p. 286).

Trata-se também, portanto, de uma luta contra um destino que parece fadado a se cumprir. Trata-se de uma luta contra a invisibilidade infligida pelo preconceito e por estigmas históricos, preconceito este conhecido por relatos, mas com muita frequência vividos na pele.

Robson - Todo mundo fala que quem mora no morro é bandido. Não é. Tem trabalhador lá em cima também. Tem gente honesta. Tem criança que nasce, cresce lá em cima, para poder ser um vereador de amanhã, um prefeito. E estão crescendo com uma mentalidade diferente. Mas todo mundo pensa que se é "negrinho" é pivete. Tantas vezes fui lá na cidade procurar emprego, - cê mora onde? Belfort Roxo. Ih, tem emprego aqui não, tem emprego para quem mora no baixada não. Por que isso? Primeiro olharam para a minha cor, depois olharam para o local onde eu morava. Isso é discriminação.[...] O que acontece com os jovens de hoje em dia? Estão vendo que as portas estão se fechando, estão correndo para o mundo do crime, estão correndo para 
o mundo das drogas, eles estão achando que ali tem dinheiro fácil. É isso que tá acontecendo. Não é porque mora na favela que é bandido, não.

No caso relatado por Robson ele não está invisível. No entanto, o que o seu possível empregador vê são apenas estigmas e preconceitos atrelados a sua imagem. E "quando visibilidade é um simples sinal de suspeita, ela é o outro lado da invisibilidade e apenas revigora seus efeitos" (SOARES, BILL; ATHAYDE, 2005 p. 188).

\section{TruculênCia e despreparo da POlícia.}

Os episódios de vulnerabilidade institucional se presentificaram nas notícias que traziam a polícia e o estado como autores de atos violentos. Em todas as rodas de conversa houve narrativas relacionadas a experiências negativas a esse respeito.

A truculenta atuação da polícia e a corrupção mascarada pelo corporativismo dessa instituição foram temas de diversos depoimentos. Medo e descrença foram sentimentos expressados nos discursos para referir-se às expectativas de ações das autoridades em favor da mudança do quadro violento.

Rodrigo - Na minha opinião tá faltando muita competência. [...] Você não vê na cara de cada um, não tá na cara da pessoa o que a pessoa é, o que a pessoa fez. Não tá na cara. Então, as pessoas pensam, os policiais pensam que você é o que eles pensam que você é. "Aquele ali é preto então ele é um trombadinha, um marginal, vamos abordar ele." Na minha opinião tem que ter uma limpeza geral dentro da polícia, nos quartéis, na sociedade. A sociedade tá muito disposta a qualquer coisa que pareça fácil demais. Então é por isso que tem muita gente se dando mal. Então, na minha opinião a gente tem que começar a limpar primeiramente a nossa casa. Nossa casa, eu me refiro aos governos, às prefeituras.

O depoimento de Rodrigo evidencia a descrença da população na eficiência e honestidade das autoridades. Segundo o jovem, é preciso realizar uma verdadeira faxina nas instituições públicas. Para analistas, o crime organizado, que se estrutura em torno do tráfico de armas e drogas, por meio de mecanismos em níveis diversos, corrompeu amplos segmentos das corporações policiais, em alguns casos atingindo desde as bases até as chefias (LEMGRUBER, MUSUMECI; CANO, 2003). Em alguns estados, a violência policial transformou-se em um problema maior e afeta diretamente as populações pobres das favelas e das periferias, que se veem encurraladas entre a violência dos grupos armados de traficantes e a violência e a corrupção de policiais (RAMOS; LEMGRUBER, 2004).

A notícia "Jovem é morto em porta de boate em Ipanema" serviu de gatilho para depoimentos referentes às fraturas do Estado em relação à segurança pública. Traz a reportagem que o jovem Daniel Duque, de 18 anos, foi morto por um PM que fazia segurança de outro jovem, filho de uma promotora. 
Vinícius - Se você vai para uma boate, normalmente você vai para se divertir, encontrar os amigos, confraternizar. Se você leva um segurança consigo? Não sei, talvez isso também reflita um pouco a violência que tem na cidade [...] e a polícia de hoje em dia, como eles estão tão agressivos.

Valdemar acompanhou o caso pelos noticiários e ressalta que o policial envolvido no crime até hoje não foi punido. Ele acredita que, por tratar-se do segurança do filho de uma promotora de Justiça, o caso não vai dar em nada, apesar das passeatas, apelos e manifestações.

Valdemar - Se eu não estou enganado esse é o caso do menino Daniel Duque, não é? [...] No máximo, esse policial vai responder a esse processo administrativamente. Esses dias eu vi na internet, ele não foi punido, ele continua fazendo a segurança do mesmo jeito. É aquilo que eu disse, eu acho isso errado, você errou, você tem que pagar. Não interessa quem ou o que você é.

No entanto, de maneira análoga, se fizeram presentes ressalvas a respeito das condições de trabalho dos policiais, seus baixos salários e a existência de um número significativo de profissionais honestos. Nessas falas, a expressão "honrar a farda" foi amplamente utilizada para designar o desejo desses policiais.

Valdemar - Falar do policial é complicado. Vê-se muito o lado do civil, e acho que tem que ver o lado do civil, mas tem que ver o lado do policial também. O cara tá estressado, não tem aquela preparação, ele não consegue ter um bom relacionamento com a sua família em casa, então ele já vai para o serviço estressado. E não tem uma psicóloga para acompanhar diariamente o policial. [...] Eu já fui abordado várias vezes por policial e ele já chega apontando arma para você, dando chute em você, ele não quer saber. Então eu acho que o policial tem que ter mais preparo para pode realizar o seu serviço da melhor forma possível para não acontecer o que aconteceu com esse jovem. [...] eu acho que o policial vive 48 horas no ar, ele sai do seu trabalho, vai fazer segurança e depois volta para o seu trabalho de novo. Então acho que isso é uma coisa que deve ser repensada, tem que dar mais suporte ao policial e não só ver as vítimas. Claro que tem que dar apoio a vítima, tem que dar assistência para as vítimas - é claro - as famílias, mas tem que dar uma assistência também ao policial. Condições para ele realizar o trabalho dele.

Em resposta ao número de notícias que trazia a polícia como autora do crime, Pedro comenta: "na certa, o PM tava fazendo o dever dele, porque se fosse um carro de assaltantes, se ele não matar os caras matam ele". Rafaela retruca que não há necessidade de "chegar atirando" e seu colega de grupo retrucou que muitos policiais estão morrendo e justificou que a polícia "hoje em dia" age dessa 
forma em virtude do medo permanente, "é por isso que tá morrendo policial direto, eles vivem em uma guerra, guerra civil e, por isso, eles saem atirando. É uma atitude brutal, mas tem o medo dele, a tensão na hora".

\section{OS JOVENS E AS POLÍTICAS PÚBLICAS: PARTICIPAÇÃO E RESPONSABILIDADE}

Em "Espaço urbano e constituição subjetiva da desigualdade social: uma possível leitura das políticas da diferença", Jobim e Souza \& Passarelli (2006) oferecem pistas para uma reflexão dos modos de ser e estar na cidade, e demonstram de que maneira a via pública cria espaços de visibilidade e anonimatos no jogo das relações sociais. Dizem os autores que:

A cidade se oferece como espaço de tensão, de confronto, de encontros e desencontros, enfim, de desafios para enfrentarmos nossos limites interiores em um permanente aperfeiçoamento daquilo que cada um pode oferecer de si na relação com o outro. Tudo isso acontece quando há situações em que as pessoas são confrontadas com barreiras potencialmente conflituosas de identidade e diferença que devem ser negociadas no curso das trocas sociais. Isto significa que as desigualdades sociais apenas indicadas pelas diferenças sociais podem ser elaboradas a partir de uma relação social ativa entre diferentes (JOBIM E SOUZA; PASSARELI, 2006, p. 124).

De maneira análoga à noção de cidade que os autores nos oferecem, as "rodas de conversa" também proporcionaram um espaço de confluência e encontro de pontos de vista heterogêneos que, devidamente organizados, auxiliam na compreensão do problema e na busca por soluções.

Assim, as "rodas de conversa" foram, sobretudo, espaços de escuta dos jovens, que possibilitaram reposicioná-los no debate acerca de políticas públicas e ações voltadas para essa população. Em seus depoimentos foi possível identificar suas principais queixas, suas aspirações e expectativas em relação ao futuro e, sobretudo, suas sugestões de enfrentamento do problema. Majoritariamente, os depoimentos falavam de uma descrença do poder instituído ligado à corrupção e à falta de interesse em melhoras significativas e verdadeiras. Em artigo sobre juventude e cidadania, José Machado Pais (2005, p. 126) questiona o motivo da ineficiência de inúmeras intervenções políticas dirigidas à juventude. $\mathrm{O}$ autor defende que os insucessos das investidas governamentais advêm de uma má investigação do campo onde se pretende intervir. "As políticas de intervenção podem ser equívocas se não se 'ancorarem' em estudos rigorosos da realidade, se a deixam perder de vista" (PAIS, 2005, p. 128). Trata-se, portanto, de consultar sobretudo aqueles a quem se pretende beneficiar. Nesse sentido, nos debates sobre políticas públicas para a juventude, os jovens não podem estar fora do processo de formulação porque são eles que irão narrar a realidade do problema que se pretende combater. E foi este exatamente o objetivo fundamental das "rodas de conversa": consultar os jovens a respeito de suas realidades e implicá-los na 
procura de alternativas para o estado de vulnerabilidade em que se encontram. Se existe a possibilidade de reversão desse quadro, ela reside em parte na análise das experiências da juventude, suas táticas e estratégias de sobrevivência. Resulta daí a importância de convocar os jovens para a busca de soluções.

Nesse sentido, mais do que constatar o problema - redundando informações já fornecidas por estudos e estatísticas - esta pesquisa é também uma sugestão de estratégia metodológica para construir com os jovens uma parceria para a formulação de políticas públicas, tendo-os como coautores na gestão de questões fundamentais que dizem respeito aos seus modos de vida, mas que não se restringem aos modos de vida dos jovens, pois os problemas da violência e suas vulnerabilidades afetam a todos e cada um de nós.

\section{Notas}

Esta pesquisa foi realizada no âmbito do Grupo Interdisciplinar de Pesquisa da Subjetividade, do Departamento de Psicologia da PUC-Rio. Este texto é parte de uma investigação mais ampla desenvolvida no contexto da Linha de Pesquisa Infâncias e Juventudes Contemporâneas e destaca parte dos resultados da dissertação de mestrado intitulada "Violência urbana e vulnerabilidades: o discurso dos jovens e as notícias de jornais", defendida por Carolina Salomão Corrêa, em 2010, no Programa de Pós Graduação em Psicologia Clínica da PUC-Rio.

2Este vídeo documentário está disponível no seguinte endereço http://gips.usuarios.rdc. puc-rio.br/video.html ou www.gipspucrio.org

Todos os participantes assinaram o Termo de Consentimento Livre e Esclarecido e foram convidados a assistir a edição preliminar do vídeo documentário "Próxima Parada: Juventude", em data e local previamente divulgado. A edição final do vídeo levou em consideração as críticas dos jovens que atenderam ao convite e compareceram à exibição do vídeo documentário em sua versão preliminar.

${ }^{4}$ O Pró Jovem é um programa do governo federal que cria oportunidades para a juventude brasileira, entre 15 e 29 anos, que vive em situação de exclusão: fora da escola, sem qualificação profissional. Segundo informações do site, "a missão do Pró Jovem é justamente reintegrar esses brasileiros ao processo educacional, promover sua qualificação profissional, garantir um auxílio financeiro durante a realização do Programa".

Inicialmente estabelecemos a faixa etária entre 18 e 24 anos, para caracterizar a juventude participante desta pesquisa, evitando menores de 18 anos por questões legais. Posteriormente, por interferência da própria realidade ampliamos para 31 anos a faixa etária dos participantes. Decidimos contar com a participação de jovens entre 18 e 31 anos para incluir os depoimentos dos jovens integrantes do Pró ljovem. Este imprevisto deixa claro que as estratégias metodológicas devem estar preparadas para se adequarem as contingências do encontro com o campo, redefinindo o que havia sido pensado previamente.

${ }^{6}$ Vale destacar que as "rodas de conversas" foram gravadas em vídeo com a autorização prévia dos integrantes, visando à produção de um material em forma de documentário, que ao valorizar o depoimento dos jovens, amplia a participação deste segmento social, além de permitir o acesso a outros jovens interessados neste debate e profissionais da área.

Os nomes dos jovens são reais uma vez que não houve nenhuma pretensão de anonimato.

Maria Rita Kehl, em seu texto "A juventude como sintoma da cultura" (ver referência na bibliografia) apresenta considerações instigantes, com base em sua experiência clínica com jovens, que nos permite problematizar o contexto familiar e o comportamento dos jovens na contemporaneidade. Consideramos pertinente trazer as reflexões da autora em diálogo com os depoimentos dos jovens e com isto potencializar o debate sobre o confronto entre gerações e a responsabilidade dos adultos no enfretamento do diálogo com a juventude atual. 


\section{REFERÊNCIAS}

ABRAMO, H. W. Considerações sobre a tematização social da juventude no Brasil. In: FÁVERO, O. et al. (Org.). Juventude e contemporaneidade. Brasília: UNESCO; MEC; ANPED, 2007. p. 73-92. Coleção Educação para todos.

ABRAMOVAY, M. et al. Juventude, violência e vulnerabilidade social na América latina: desafios para políticas públicas. Brasília: UNESCO, BID, 2002.

ACIDENTES: 1/3 das vítimas é jovem. O Globo, Rio de Janeiro, 27 maio 2008. Editoria Rio, p. 11.

ADORNO, R. C. F. Um olhar sobre os jovens e sua vulnerabilidade social. São Paulo: AAPCS -Associação de Apoio ao Programa Capacitação Solidária, 2001.

BOLETIM da violência. $O$ Globo, Rio de Janeiro, 22 set. 2008. Primeiro Caderno, Editoria O País, Eleições 2008, p. 3.

CASTRO, M. G.; ABRAMOVAY, M. Juventudes no Brasil: vulnerabilidades negativas e positivas, desafiando enfoques de políticas públicas. In: PETRINI, J. C.; CAVALCANTI, V. R. S. (Org.). Familia, sociedade e subjetividades: uma perspectiva multidisciplinar. Petrópolis: Vozes, 2005. p. 54-83.

BAUMAN, Z. O mal-estar da pós modernidade. Rio de Janeiro: J. Zahar, 1998.

DAYRELL, J. O jovem como sujeito social. In: FÁVERO, O. et al. (Org.). Juventude e contemporaneidade. Brasília: UNESCO; MEC; ANPED, 2007. p. 155-178. Coleção Educação para todos.

DECRETADA prisão de militares. $O$ Globo, Rio de Janeiro, 16 jun. 2008. Editoria Rio, p. 8.

EHRENBERG, A. La fatigue d'être soi: dépression et société. Paris: Odile Jacob, 2000 .

GONÇALVES, H. S. Juventude Brasileira, entre a tradição e a modernidade. Tempo Social revista de sociologia da USP, São Paulo, v. 17, n. 2, p. 207-219, nov. 2005. .

JOBIM E SOUZA, S.; PASSARELLI, C. A. Espaço urbano e constituição subjetiva da desigualdade: uma possível leitura das políticas da diferença. In: SPINK, M. J.; SPINK, P. (Org.). Práticas cotidianas e a naturalização da desigualdade: uma semana de notícias nos jornais. São Paulo: Cortez, 2006. p. 109-125. 
JOVEM é morto na porta de boate em Ipanema. O Globo, Rio de Janeiro, 29 jun. 2008. Editoria Rio, p. 24.

LEMGRUBER, J.; MUSUMECI, L.; CANO, I. Quem vigia os vigias? Um estudo sobre controle externo das polícias no Brasil. Rio de Janeiro: Record, 2003.

LIPOVETSKY, G.; CHARLES, S. Os tempos hipermodernos. São Paulo: Barcarolla, 2004.

KEHL, M. R. A juventude como sintoma da cultura. In: NOVAES, R.; VANNUCHI, P. (Org.). Juventude e sociedade: trabalho, educação, cultura e participação. São Paulo: Fundação Perseu Abramo, 2004. p. 89-114.

MESQUITA NETO, P. et al. A Violência do cotidiano. Rio de Janeiro: Konrad Adenauer Stiffung, 2001. Coleção Cadernos Adenauer.

MILITARES são presos por entregar jovens para o tráfico. $O$ Globo, Rio de Janeiro, 16 jun. 2008. Capa.

MORRE jovem baleado em festa em São Gonçalo. $O$ Globo, Rio de Janeiro, 15 set. 2008. Editoria Rio, p. 11.

MORTE de jovens por PMs causa revolta. O Globo, Rio de Janeiro, 15 jul. 2008. Editoria O País, p. 9.

MORTE no navio: Isabella bebeu demais e foi asfixiada pelo vômito, diz a PF. $O$ Globo, Rio de Janeiro, 23 dez. 2008. Editoria O País, p. 4.

PAIS, J. M. As múltiplas 'caras' da cidadania. In: CASTRO, L. R.; CORREA, J. (Org.) Juventude contemporânea: perspectivas nacionais e internacionais. Rio de Janeiro: Nau, 2005. p. 107-133.

PERES, M. F. T. Homicídios, risco e vulnerabilidade: para uma discussão da dinâmica da vitimização por homicídios. In: CRUZ, M. G. V.; BATITUCCI, E. C. (Org.). Homicídios no Brasil. Rio de Janeiro: FGV, 2007. p. 125-139.

POLÍCIA prende 38 jovens com drogas em rave. O Globo, Rio de Janeiro, 02 jun. 2008. Editoria Rio, p. 9.

PRÓXIMA parada: juventude. Produção de Carolina Salomão Corrêa. Rio de Janeiro: Departamento de Psicologia da PUC-Rio, 2010. Vídeo documentário. Disponível em: <http://gips.usuarios.rdc.puc-rio.br/video.html>. Acesso em: 10 abr. 2010. 
RAMOS, S.; LEMGRUBER, J. Criminalidade e respostas brasileiras à violência. In: Observatório da Cidadania. Rio de Janeiro: IBASE, 2004. p. 45-52.

SANT'ANNA, A. Homicídios entre adolescentes no sul do Brasil: situações de vulnerabilidade segundo seus familiares. Caderno de Saúde Pública, Rio de Janeiro, v. 21, n. 1, p. 120-129, jan.-fev. 2005. .

SOARES, L. E.; MV BILL; ATHAYDE, C. Cabeça de porco. Rio de Janeiro: Objetiva, 2005.

SPINK, M. J. (Org.). Práticas cotidianas e a naturalização da desigualdade: uma semana de notícias nos jornais. São Paulo: Cortez, 2006.

WAISELFISZ, J. J. Mapa da violência IV: jovens do Brasil, UNESCO, 2005.

Recebido em: 09 de agosto de 2010 Aceito em: 14 de setembro de 2011 
